\title{
Appetite, oral health and weight loss in community-dwelling older men: an observational study from the Concord Health and Ageing in Men Project (CHAMP)
}

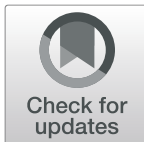

Sachiko Takehara ${ }^{1,2^{*}}$ D, Vasant Hirani ${ }^{3}$, F. A. Clive Wright ${ }^{1,4,5}$, Vasi Naganathan ${ }^{1,4,5}$, Fiona M. Blyth ${ }^{4,6}$, David G. Le Couteur ${ }^{1,4,5}$, Louise M. Waite ${ }^{1,4,5}$, Markus J. Seibel ${ }^{4,7}$, David J. Handelsman ${ }^{7}$ and Robert G. Cumming ${ }^{1,6}$

\begin{abstract}
Background: Unintended weight loss and the reduction in appetite are common phenomenon among older people. Reduced appetite has been linked to medication related reductions in saliva production, reduced taste ability and poor oral health. Poor appetite can result in reduced nutrient intake ensuing weight loss. It is possible that poor appetite is a mediating step on the causal pathway between oral health and weight loss. This study investigates whether poor oral health and loss of appetite are related to weight loss.

Methods: This is an observational study where data were obtained from the Concord Health and Ageing in Men Project (CHAMP). Information on socio-demographics, appetite and health related behavior was collected by selfcompleted questionnaire. Intraoral assessment was conducted by calibrated oral health therapists. Height and weight were measured by trained staff. Regression analysis investigated associations between oral health and appetite as risk factors for weight loss.
\end{abstract}

Results: Participants included 542 community dwelling older males. 99 older men (18.3\%) experienced 5\% or more weight loss over 3 years. Men who lost weight from baseline had lower BMI and lower body weight, had higher prevalence of frailty and depression, reported poorer appetite, and had fewer teeth (13.8 \pm 9.5$)$ than those who did not lose weight (16.3 \pm 9.3 ). Before adjustment, the prevalence ratio (PR) for weight loss was 1.76 (95\% Confidence Interval (Cl), 1.19-2.59) for participants with 0-19 natural teeth present compared to those with 20 or more teeth. When adding appetite and other variables to the model, the PR for number of teeth and weight loss was unchanged: $1.78(95 \% \mathrm{Cl}, 1.06-3.00)$. The mediation analysis showed that the indirect effect of appetite on the association between number of natural teeth on weight loss was not found to be significant.

(Continued on next page)

\footnotetext{
* Correspondence: takehara.ohp@gmail.com

${ }^{1}$ Centre for Education and Research on Ageing, Concord Clinical School, The

University of Sydney, and the Ageing and Alzheimer's Institute, Concord

Repatriation General Hospital, Sydney Local Health District, Concord, NSW,

Australia

${ }^{2}$ Department of Public Health, Tokyo Women's Medical University, Tokyo,

Japan

Full list of author information is available at the end of the article
}

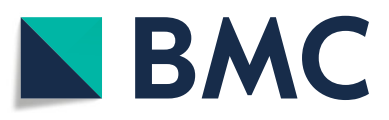

(- The Author(s). 2021 Open Access This article is licensed under a Creative Commons Attribution 4.0 International License, which permits use, sharing, adaptation, distribution and reproduction in any medium or format, as long as you give appropriate credit to the original author(s) and the source, provide a link to the Creative Commons licence, and indicate if changes were made. The images or other third party material in this article are included in the article's Creative Commons licence, unless indicated otherwise in a credit line to the material. If material is not included in the article's Creative Commons licence and your intended use is not permitted by statutory regulation or exceeds the permitted use, you will need to obtain permission directly from the copyright holder. To view a copy of this licence, visit http://creativecommons.org/licenses/by/4.0/. The Creative Commons Public Domain Dedication waiver (http://creativecommons.org/publicdomain/zero/1.0/) applies to the data made available in this article, unless otherwise stated in a credit line to the data. 
(Continued from previous page)

Conclusion: This study found that number of natural teeth present and appetite are independently related to weight change among elderly men in Australia. Tooth loss can increase the risk of swallowing difficulty leading to change in food preference, avoidance of foods and a decrease in energy intake. Our study showed the importance of oral health interventions to encourage maintenance of 20 or more natural teeth in older people.

Keywords: Weight loss, Oral health, Tooth loss, Older men, Appetite

\section{Background}

Among older people, unintended weight loss is a common phenomenon caused by various pathophysiological, socioeconomic and mental health factors. Past observational studies have suggested weight change is a predictor of outcomes such as premature death and disability among older people. Weight loss of 3 to $5 \%$ within 2 to 3 years is associated with a higher risk of mortality in older people $[1,2]$. One of the factors associated with weight loss is poor oral health, as suggested by recent crosssectional and cohort studies [3-5].

Reduced appetite in older people has been linked to medication related reductions in saliva production, reduced taste ability and poor oral health [6]. Poor appetite, often termed the anorexia of ageing, can result in reduced food and nutrient intake, changes in food choice, and ensuing weight loss $[6,7]$. It is possible that poor appetite is a mediating step on the causal pathway between oral health and weight loss. Several studies have found that oral health is associated with body weight [3, 4, 8, 9]. However, to our knowledge, there have been no studies that have investigated both poor oral health and poor appetite with regards to weight loss among an older population. The aim of this study was to investigate whether poor oral health and loss of appetite are related to weight loss in community dwelling older males in Australia.

\section{Methods}

\section{Study participants}

The current observational study was performed with data from the 5 (2012-2013) and 8 (2015-2016) year assessments of the Concord Health and Ageing in Men Project (CHAMP), a longitudinal epidemiologic study of older men in New South Wales (NSW), Australia (Fig. 1). The baseline study was conducted from 2005 to 2007, with male participants aged 70 years and over, living in a defined geographical region (Local Government Areas of Burwood, Canada Bay and Strathfield) [10]. The sampling frame was the NSW Electoral Roll, where registration is compulsory for all citizens of Australia for a representative population sample. The study design has been reported in detail elsewhere [10]. All the eligible men in the study area were invited to join the study excluding men living in residential aged care facilities. In 5th and 8th -year assessments, all older males who participated in the previous assessments were invited to participate in this assessment. All participants were given a verbal explanation of study purpose and methods involved and signed consent forms.

\section{Anthropometric data}

Height and weight were evaluated twice: first at the 5year follow-up (2010-2012); and then at the 8-year (2015-2016) follow-up study. Height was measured using the Harpenden Stadiometer (Dyfed, UK). Weight was measured wearing light indoor clothing and without footwear on a digital weight scale (Tanita BWB-600). The same scale was used for all measures to maintain measurement fidelity. Body mass index (BMI) was calculated dividing weight $(\mathrm{kg})$ by the square of height $(\mathrm{m})$ [11].

\section{Weight loss}

Weight change of participants over the 3-year period was evaluated by comparing current weight at the 8year follow-up assessments to weight at the 5-year follow-up assessments: [(weight) - (weight 3-years before)] / (weight) $\times 100$. We defined significant weight loss as a loss of $5 \%$ or more over a 3 -year period $[2,12]$. Participants were dichotomized into two groups: (1) those who had a weight loss of $5 \%$ or more over the previous 3 years; and (2) those who had stable weight (either less than $5 \%$ weight gain or less than $5 \%$ weight loss), or had gained weight of $5 \%$ or more in the previous 3 -years.

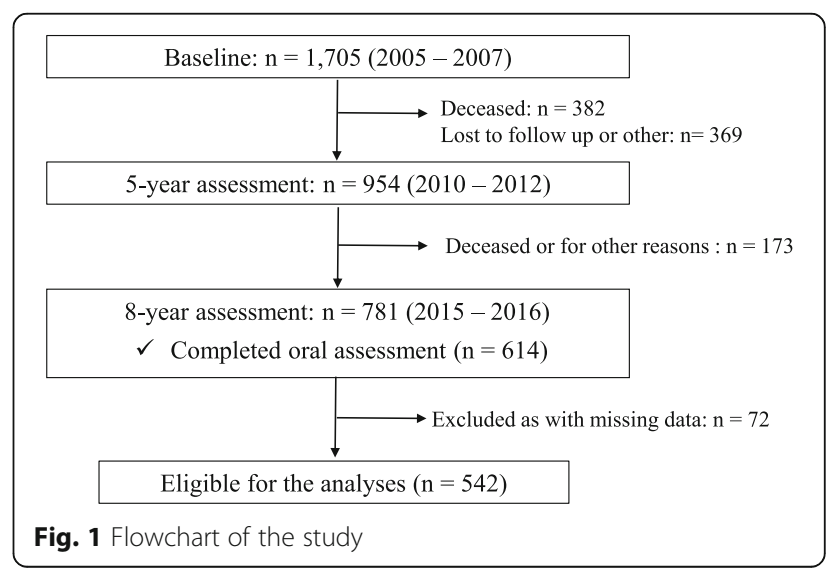




\section{Oral health assessment}

Data regarding oral health was obtained from the 8-year assessment of CHAMP study when the dental study was conducted for the first time.

\section{Dentition and dentures}

Standard intra-oral assessments were conducted by two calibrated oral health therapists using protocols consistent with Australian dental data collection standards [13]. Calibration procedure and examiners' reliability were reported previously [13]. Tooth loss, replacement teeth and number of teeth present including 3rd molars were recorded from each participant. Functional Tooth Units (FTUs) were calculated as described by Kayser and Ueno et al. [14, 15]. The maximum number of FTUs is 12 units. FTUs measure the contact of opposing posterior teeth and are therefore used as an estimate of masticatory efficiency $[14,15]$. The number of natural teeth present was categorized as either (a) 0 to 19 ,or (b) 20 or more [14]. Denture wearing status was classed into three categories: (1) full dentures for both mandibular and maxilla, (2) full denture for either mandibular or maxilla, and/or partial denture, and (3) no denture.

\section{Mouth dryness}

Resting saliva production was estimated by the visual screening method described by Walsh [16]. Calibrated oral health therapists gently rolled subjects' lower lip out and down, then dried an area on the inside surface of the lip with a gauze, and then observed the formation of droplets of saliva on the lip over a $60 \mathrm{~s}$ period. The results were categorized into three groups based on saliva droplets formation: (1) droplet formation within $30 \mathrm{~s}$, (2) droplet formation between 30 and $60 \mathrm{~s}$, or (3) no droplet formation after $60 \mathrm{~s}$. Categories 2 and 3 were classified as 'dry mouth' for the analyses.

\section{Chewing capacity and oral health variables}

Chewing capacity was evaluated by asking participants whether they were able to chew each of the 11 items on a list of foods ranging from 'soft' through 'hard' texture. Details of the questionnaires and assessment processes have been reported in previous studies [10, 13, 17]. Chewing assessment was based on methods described by Leake, but modified for the ethnic characteristics of the CHAMP study population, which included a high proportion of Italian and Greek migrants [13, 18]. Answers to each food item were dichotomized as 'yes' or 'no/not applicable'. Total responses were later dichotomized as "no problem" in chewing if participants answered yes (able to chew) to over 10 food items or as "limited" chewing capacity if they answered yes to fewer than 10 food items.

Information on self-evaluated oral health and difficulties in swallowing certain foods were also obtained through a self-completed questionnaire, and then dichotomized as either: (a) self-rated oral health (excellent/very good/good vs. fair/poor), and (b) swallowing difficulty (never/hardly ever vs. occasionally/fairly often/ very often).

Dietary characteristics (that included both appetite and having a special diet such as low fat diet, diabetic diet, and lactose diet advised by a health professional) were evaluated professionally by the study dietitian. Data were dichotomized as either having a special diet advised by a health professional or not ('yes' vs. 'no'). Appetite was assessed by applying the question: how would you describe your appetite? The response options were: 'very good', 'good', 'average', 'poor', and 'very poor'. The responses were then categorized into two groups: 'very good, good' vs. 'average, poor, very poor. Poor appetite was defined as 'average', 'poor', and 'very poor'. This categorization was based on a previous study by van der Meij et al [19].

\section{Covariates}

Sociodemographic characteristics (age, country of birth, income, marital status, post-school education), behavioral (drinking status, smoking status, and physical activity) were collected through self-completed questionnaires. Country of birth was categorized into three groups: Australia; Greece or Italy; and other countries. An income-based assessment was used to characterize income levels: the lowest income category was categorized as 'all income from aged pension only'; the middle category was income received from 'age pension plus other income'; and the highest category was income from any possible combinations of superannuation, private income, own business/farm/partnership, wage or salary income, repatriation or veteran's pension, or other income' (but ineligible for any age pension due to high income). Marital status was categorized as 'married or having a partner', 'widowed', 'divorced or separated', and 'never married'. Post school qualification was categorized as having a postsecondary school qualification or not. Smoking status was classified into two categories: 'never smoked' or 'current/ previous smoker'.

Comorbidities were assessed using a standardized questionnaire, in which participants indicated they had been told by a physician whether they had one or more of the following health conditions: diabetes, thyroid dysfunction, osteoporosis, Paget's disease, stroke, Parkinson's disease, kidney stones, dementia, depression, epilepsy, hypertension, heart attack, myocardial infarction, angina, congestive heart failure, intermittent claudication, chronic obstructive lung disease, liver disease, chronic kidney disease, cancer, osteoarthritis or gout [10]. The number of comorbidities were categorized into either ' 0 3' or ' $\geq$ 4' comorbidities. 
Physical activity was evaluated by asking 'Do you take walks for exercise, daily or almost every day?' The answers were dichotomized as 'yes, (daily or almost every day)' or 'no'.

Depressive symptoms were measured using the short, 15-item version of the Geriatric Depressive Scale (GDS) $[20,21]$. A score of five or more points was used as the cut point for clinically important depressive symptoms [22]. Frailty was assessed by trained staff using the five criteria of weight loss/shrinking, weakness, exhaustion, slowness and low activity, following the definition by Fried et al. slightly modified for CHAMP [23, 24]. CHAMP men were categorized as 'frail' if they had three or more frailty criteria, 'pre-frail' with one or two criteria and 'robust' (not frail) without any criteria.

\section{Ethics statement}

The study was performed in accordance with World Medical Association Declaration of Helsinki, and the study protocol and consent procedures were approved by Sydney Local Health District Human Ethics Research Committee (Approval No. HERC/14/CRGH/17).

\section{Statistical analysis}

Chi-squared tests were utilized to examine the bivariate associations between weight loss (weight loss of $5 \%$ or more vs. weight loss less than $5 \%$, or weight gain) and categorical variables such as country of birth, income, marital status, post-school qualification, drinking status, smoking status, comorbidities, having a special diet advised by a health professional, appetite, physical activity, frailty and depression. Mean values of age, BMI and body weight (at the time of study and 3-years before), total-FTU and number of teeth present by weight loss category were analyzed using Student's t-test. Chi-squared tests were performed to examine the relationship between weight loss and oral health categorical variables and between appetite and oral health variables (number of present teeth, FTU, chewing capacity, swallowing difficulty, mouth dryness, self-evaluated oral health).

Poisson models with robust variance estimation were used to examine the association between number of natural teeth and weight loss. Model 1 only included number of teeth and weight loss. Model 2 was adjusted for appetite. In the model 3, age (as a continuous variable), income, comorbidities, country of birth, post school qualification, BMI 3-years previously (as a continuous variable), smoking status, having a special diet and denture wearing status were further entered. Prevalence ratios (PR) and their 95\% confidence intervals (CI) were calculated for these models. Calculating variance inflation factors in each Poisson model allowed the detection of any presence of multicollinearity [25]. In order to examine if appetite mediated the relationship between number of teeth present and weight loss, the bootstrapping method was employed using PROCESS macro for SPSS (version 3.5) [26]. The number of bootstrap samples was set to 5000. A two-sided $p$-value $<0.05$ was used as the level of statistical significance. Statistical analyses were performed using Statistical Package for Social Sciences (SPSS) for Windows, version 19.0.0 (SPSS, Inc., Chicago IL).

\section{Results}

There were 781 participants who competed the selfcompleted questionnaire and 614 men who completed the oral health assessment in the 8-year study. After excluding participants with any of missing values, data were available for 542 CHAMP men who completed the oral health assessment, dietary assessment and body measurement. The mean age (SD) of participants at the 5-year of the study was 80.3 years (4.1). The mean BMI (SD) of the men at that time was 27.9 (4.2) and 27.8 (4.3) at 5-year of the study. There were 99 older men $(18.3 \%)$ who experienced $5 \%$ or more weight loss over the preceding 3 years, with 389 older men (71.7\%) who maintained a relatively stable weight with either less than $5 \%$ weight gain or a weight loss of less than $5 \%$. The remaining 54 older men $(10.0 \%)$ had $5 \%$ or more weight gain. Table 1 (a), (b) shows the characteristics of study participants at the 5 and 8-year assessments by weight loss. As compared to men with stable weight or weight gain of $5 \%$ or more, the men who lost weight $5 \%$ or more had lower BMI and body weight, higher prevalence of frailty and depression, and were more likely to report poor appetite at the 8-year assessment.

The mean number of natural teeth present was $16.3 \pm$ 9.3 among men with stable weight or $5 \%$ or more weight gain. This was statistically significantly higher than among those who lost weight by $5 \%$ or more $(13.8 \pm 9.5$, $p=0.02$ ). Table 2 presents data on oral health status by weight loss category. $52.6 \%$ of men with stable weight or $5 \%$ or more weight gain had 0-19 natural teeth, compared to $68.7 \%$ of men who lost $5 \%$ or more weight.

Characteristics of oral health by appetite are presented in Table 3. Among the study participants, 340 people $(62.7 \%)$ reported their appetite as 'Very good' or 'Good'. There were no statistically significant differences in total FTUs or number of natural teeth present by appetite. However, participants who reported appetite as 'Average', 'Poor', or 'Very poor' were more likely to wear dentures, have limited chewing capacity, mouth dryness, and have lower self-evaluated oral health.

Table 4 provides findings from Poisson regression models where weight change (' $5 \%$ or more weight loss' vs. 'stable weight or weight gain') was the dependent variable and the variable - number of natural teeth present - was the independent variable. There was a statistically significant association (model 1) between number 
Table 1 Distribution of demographic and health conditions of participants by weight loss

\begin{tabular}{|c|c|c|c|c|c|}
\hline \multicolumn{6}{|c|}{ a. Average BMI, body weight and age (mean \pm SD) } \\
\hline & Variables & $\begin{array}{l}\text { Total population } \\
(N=542)\end{array}$ & $\begin{array}{l}\text { Stable or Weight gain } \\
\geq 5 \%^{\text {a }}(N=443)\end{array}$ & $\begin{array}{l}\text { Weight loss } \geq 5 \%{ }^{\mathrm{b}} \\
(N=99)\end{array}$ & $p$ value \\
\hline \multirow[t]{3}{*}{ 5th year assessment (as baseline data) } & Age & $80.3 \pm 4.1$ & $80.2 \pm 4.0$ & $81.5 \pm 4.2$ & 0.08 \\
\hline & BMI & $27.8 \pm 4.3$ & $27.8 \pm 4.2$ & $28.1 \pm 4.6$ & 0.48 \\
\hline & Body weight & $79.5 \pm 13.2$ & $79.4 \pm 12.9$ & $80.0 \pm 14.3$ & 0.68 \\
\hline \multirow[t]{2}{*}{ 8th year assessment } & BMI & $27.9 \pm 4.2$ & $28.2 \pm 4.0$ & $26.3 \pm 4.5$ & $<0.001$ \\
\hline & Body weight & $78.7 \pm 13.5$ & $79.9 \pm 13.1$ & $73.2 \pm 13.6$ & $<0.001$ \\
\hline
\end{tabular}

b. Demographic, comorbidities, and health related characteristics at 8th year assessments

variables

Total population $(N=542)$

n

(\%)
Stable or Weight gain $\geq 5 \%^{\mathrm{a}}(N=443)$
n

(\%)
Weight loss $\geq 5 \%{ }^{\mathrm{b}}$ $(N=99)$

n

(\%)

\section{Demographic and health behaviours}

\section{Country of Birth:}

Australia
Greece/ltaly
Other

$\begin{array}{ll}286 & (52.8) \\ 123 & (22.7) \\ 133 & (24.5) \\ 208 & (38.4)\end{array}$

Post school education (No education)

208

$(38.4)$

Income:

Pension only
Pensions + other
Other income

\section{Marital status:}

Married/Partner

Widowed

Divorced/separated

Never married

\section{Drinking status:}

Life-long abstainer
Ex-drinker
Safe-drinker
Unsafe-drinker
Smoking status (Current or previous smoker)

\section{Comorbidities}

Comorbidities $\geq 4$

Arthritis

Diabetes mellitus

Heart attack

Stroke

Hypertension

Cancer

\section{Health related characteristics}

Take walks daily/almost everyday

\section{Frailty:}

robust
155

283

117

108

299

104

285

137
(8.3)

(14.0)

(70.7)

(59.6)

(28.6)

(52.2)

(21.6)

(19.9)

(55.2)

(52.6)

(25.3)
239

102

102

171

164

106

173

326

75

16

26

\section{3}

56

323

31

260

121

234

87

86

34

245

84

236

124

$(54.0)$
$(23.0)$
$(23.0)$
$(38.6)$

47

(47.5)

(21.2)

(31.3)

(37.4)

0.22

31

37

(37.0)

(23.9)

(73.6)

(16.9)

(3.6)

(5.9)

(44.4)

(22.2)

(33.3)

0.38

33

(69.7)

0.56

(22.2)

(2.0)

(6.1)

6

(12.6)

(60.6)

0.07

(7.0)

(7.1)

(58.7)

(63.6)

0.43

$$
\text { (27.3) }
$$

(52.8)

(19.6)

(19.4)

(7.7)

(55.3)

(19.0)

(34.3)

0.18

(49.5)

0.58

(30.3)

0.03

(22.2)

0.53

(12.1)

0.16

(54.5)

0.91

(20.2)

0.43

(53.3)

49

(49.5)

0.50 
Table 1 Distribution of demographic and health conditions of participants by weight loss (Continued)

\begin{tabular}{|c|c|c|c|c|c|c|c|}
\hline pre-frail & 311 & $(57.4)$ & 261 & $(58.9)$ & 50 & $(50.5)$ & $<0.001$ \\
\hline frail & 94 & $(17.3)$ & 58 & $(13.1)$ & 36 & $(36.4)$ & \\
\hline Depression (Geriatric Depression Scale $\geq 5$ ) & 90 & (16.6) & 66 & $(14.9)$ & 24 & $(24.2)$ & 0.04 \\
\hline Special diet advised by a health professional & 59 & $(10.9)$ & 48 & $(10.8)$ & 11 & $(11.1)$ & 0.94 \\
\hline \multicolumn{8}{|l|}{ Appetite: ${ }^{c}$} \\
\hline Very good & 107 & $(19.7)$ & 97 & $(21.9)$ & 10 & $(10.1)$ & \\
\hline Good & 233 & (43.0) & 193 & (43.6) & 40 & $(40.4)$ & \\
\hline Average & 172 & (31.7) & 133 & (30.0) & 39 & (39.4) & 0.01 \\
\hline Poor & 24 & $(4.4)$ & 16 & (3.6) & 8 & $(8.1)$ & \\
\hline Very poor & 6 & (1.1) & 4 & $(0.9)$ & 2 & (2.0) & \\
\hline
\end{tabular}

${ }^{a}$ Stable weight with either less than $5 \%$ weight gain or less than $5 \%$ weight loss, or had gained weight $5 \%$ or more in the previous 3 -years between 5 -year and 8-year assessments

${ }^{\mathrm{b}}$ Weight loss of 5\% or more over 3-years between 5-year and 8-year assessments

c Appetite was assessed by applying the question: how would you describe your appetite? The response options were: 'very good', 'good', 'average', 'poor', or 'very poor'

of teeth and weight loss $(\mathrm{PR}=1.76,95 \% \mathrm{CI}=1.19-2.59)$. Similarly, the association remained $(\mathrm{PR}=1.73,95 \% \mathrm{CI}=$ 1.18-2.55) after being adjusted for appetite (model 2). The addition of appetite (model 2) did not change the strength of association between number of teeth and weight loss. Model 2 was further adjusted by the variables: age (as continuous variable), income, co-morbidities, country of birth, post school qualification, BMI at 3-year interval before (as continuous variable), smoking status, having special diet and denture wearing status (model 3). The association between number of teeth present and weight loss remained significant in this fully adjusted model $3(P R=1.78,95 \%$ $\mathrm{CI}=1.06-3.00)$.

To investigate whether the number of natural teeth is independently associated with weight loss, a simple mediation analysis was performed. The outcome variable for the analysis was weight loss, the predictor variable was number of natural teeth, and the mediator was appetite. The mediating effect of appetite on weight loss was not found to be significant (effect $=-0.02,95 \% \mathrm{CI}(-0.09,0.05))$.

\section{Discussion}

This study provides new epidemiological evidence supporting the association of oral health (represented by number of natural teeth present), appetite and weight loss in community dwelling older men in Australia. A number of previous publications have reported poor appetite as an important determinant of nutritional deficiency and of weight loss among older people $[6,7,19]$. Poor oral health, including wearing dentures, poor dentition, and mouth dryness, are known to be associated with loss of appetite [27]. These previous findings suggest that poor oral health might contribute to weight loss with poor appetite as a mediator. However, our

Table 2 Oral health status by weight loss

\begin{tabular}{|c|c|c|c|c|c|c|c|}
\hline \multirow[t]{2}{*}{ Variables } & \multicolumn{2}{|c|}{$\begin{array}{l}\text { Total population } \\
(N=542)\end{array}$} & \multicolumn{2}{|c|}{$\begin{array}{l}\text { Stable or Weight gain } \\
\geq 5 \%^{\mathrm{a}}(N=443)\end{array}$} & \multicolumn{2}{|c|}{$\begin{array}{l}\text { Weight loss } \geq 5 \%^{b} \\
(N=99)\end{array}$} & \multirow[b]{2}{*}{$p$ value } \\
\hline & $\mathrm{n}$ & (\%) & $\mathrm{n}$ & (\%) & $\mathrm{n}$ & $(\%)$ & \\
\hline Has $<20$ natural teeth & 301 & $(55.5)$ & 233 & $(52.6)$ & 68 & $(68.7)$ & $<0.01$ \\
\hline \multicolumn{8}{|l|}{ Denture wearing status } \\
\hline Full denture (mandibular+maxillary) & 71 & $(13.1)$ & 55 & $(12.4)$ & 16 & $(16.2)$ & \\
\hline Single full denture and/or partial denture & 238 & $(43.9)$ & 190 & $(42.9)$ & 48 & $(48.5)$ & 0.21 \\
\hline No denture & 233 & $(43.0)$ & 198 & $(44.7)$ & 35 & $(35.4)$ & \\
\hline Limited chewing capacity ${ }^{c}$ & 152 & $(28.0)$ & 119 & $(26.9)$ & 33 & $(33.3)$ & 0.22 \\
\hline Swallowing difficulty (Occasionally/Fairly often/Very often) & 65 & $(12.0)$ & 46 & $(10.4)$ & 19 & $(19.2)$ & 0.03 \\
\hline Mouth dryness (Dry: no droplet within 30 s) & 346 & $(63.8)$ & 280 & $(63.2)$ & 66 & $(66.7)$ & 0.56 \\
\hline Self-evaluated oral health (Fair/Poor) & 151 & $(27.9)$ & 121 & $(27.3)$ & 30 & $(30.3)$ & 0.54 \\
\hline
\end{tabular}

${ }^{a}$ Stable weight with either less than $5 \%$ weight gain or less than $5 \%$ weight loss, or had gained weight $5 \%$ or more in the previous 3 -years between 5 -year and 8 -year assessments

${ }^{\mathrm{b}}$ Weight loss of $5 \%$ or more over 3-years between 5-year and 8-year assessments

' Chewing capacity were evaluated by asking "Are you currently able to chew?" for 11 food items. Subjects who answered "yes" to 10 - 11 food items were classified as "no problem", or otherwise classified as "limited" 
Table 3 Oral health status by appetite

\begin{tabular}{|c|c|c|c|c|c|c|c|}
\hline \multirow[t]{2}{*}{ Variables } & \multicolumn{2}{|c|}{$\begin{array}{l}\text { Total population } \\
(N=542)\end{array}$} & \multicolumn{2}{|c|}{$\begin{array}{l}\text { Good appetite }{ }^{b} \\
(N=340)\end{array}$} & \multicolumn{2}{|c|}{$\begin{array}{l}\text { Poor appetite } \\
(N=202)\end{array}$} & \multirow[b]{2}{*}{$p$ value } \\
\hline & & & $\mathbf{n}$ & $\%$ & $\mathbf{n}$ & $\%$ & \\
\hline Number of natural teeth (mean \pm S.D.) & \multicolumn{2}{|c|}{$15.8 \pm 9.3$} & \multicolumn{2}{|c|}{$16.1 \pm 9.4$} & \multicolumn{2}{|c|}{$15.4 \pm 9.2$} & 0.39 \\
\hline Total FTU (mean \pm S.D.) & \multicolumn{2}{|c|}{$7.7 \pm 3.7$} & \multicolumn{2}{|c|}{$7.7 \pm 3.8$} & \multicolumn{2}{|c|}{$7.7 \pm 3.6$} & 0.98 \\
\hline Has $<20$ natural teeth & 301 & $(55.5)$ & 181 & $(53.2)$ & 120 & $(59.4)$ & 0.162 \\
\hline \multicolumn{8}{|l|}{ Denture wearing status } \\
\hline Full denture (mandibular + maxillary) & 71 & $(13.1)$ & 45 & $(13.2)$ & 26 & $(12.9)$ & \\
\hline Single full denture and/or partial denture & 238 & $(43.9)$ & 134 & $(39.4)$ & 104 & $(51.5)$ & \multirow[t]{2}{*}{0.02} \\
\hline No denture & 233 & $(43.0)$ & 161 & $(47.4)$ & 72 & $(35.6)$ & \\
\hline Limited chewing capacity $^{c}$ & 152 & $(28.0)$ & 82 & (24.1) & 70 & $(34.7)$ & 0.01 \\
\hline Swallowing difficulty (Occasionally/Fairly often/Very often) & 65 & (12.0) & 41 & $(12.1)$ & 24 & $(11.9)$ & 0.95 \\
\hline Mouth dryness (Dry: no droplet within 30 s) & 346 & (63.8) & 204 & $(60.0)$ & 142 & $(70.3)$ & 0.02 \\
\hline Self-evaluated oral health (Fair/Poor) & 151 & $(27.9)$ & 80 & (23.5) & 71 & $(35.1)$ & $<0.01$ \\
\hline
\end{tabular}

study has shown that poor oral health is an independent risk factor for weight loss in older men.

Poor appetite is frequently observed in association with ageing [28]. It is important to note that nearly $40 \%$ of our participants reported poor appetite. This prevalence is consistent with previous studies [28]. We found that men with poorer appetite were more likely to wear dentures, have limited chewing capacity, have mouth dryness, and have lower self-evaluated oral health status. Dormenval et al. also reported that dry mouth is associated with wearing dentures, difficulty in chewing and swallowing, and poorer appetite among hospitalized elderly patients in Switzerland [29]. Kamel et al. examined an adult population in the United Kingdom, and found that dry mouth, or reduced salivary secretion was associated with poorer taste sensitivity and reduced health- related quality of life [30]. Furthermore, Donini et al. examined hospitalized elderly in Italy, reporting

Table 4 Multivariate poisson regression on weight loss (reference: people with stable weight, or weight gain $\geq 5 \%$ in the previous 3-years)

\begin{tabular}{ll}
\hline & PR (95\% Cl) \\
\hline Model 1 & \\
$\quad$ Natural teeth present (reference: $20 \sim 32): 0 \sim 19$ & $1.78(1.06-3.00)$ \\
Model 2 (adjusted by appetite) & \\
$\quad$ Natural teeth present (reference: $20 \sim 32): 0 \sim 19$ & $1.73(1.18-2.55)$ \\
Model 3 (adjusted by multivariables ${ }^{\mathrm{a}}$ ) & \\
$\quad$ Natural teeth present (reference: $20 \sim 32): 0 \sim 19$ & $1.77(1.05-2.97)$ \\
$\begin{array}{l}\text { a: It includes following variables: appetite, age, income, comorbidities, country } \\
\text { of birth, post school qualification, BMl 3-year before, smoking, special diet and } \\
\text { denture wearing status }\end{array}$
\end{tabular}

that those with poor appetite had limited chewing capacity, swallowing difficulty, and reduced tasted sensitivity [31]. All these reports are consistent with the findings from the present study. However, specific biological mechanisms behind these associations between appetite and oral health are not understood [28].

Only a small number of studies have focused on the association between oral health status and weight loss [3-5]. These previous studies have findings that are consistent with ours [3-5]. However, to our knowledge, no previous studies have considered both number of natural teeth present and appetite in relation to weight loss.

Weyant et al. analyzed data from the Health $A B C$ study, a longitudinal cohort study among a communitydwelling, well-functioning population aged 65 and older in Pennsylvania and found that weight loss was associated with having a compromised oral health status, including lower number of natural teeth present and gingival inflammation [3]. Although the weight of participants was measured twice, oral health examinations were conducted only once. Ritchie et al. conducted a cross-sectional study among community dwelling people aged 70 and older in UK and found that edentate people (having no natural teeth) were more likely to experience weight loss of $4 \%$ over a 1 year period [4]. Again, oral health status was assessed by dental professionals only at the baseline, and participants' weight at the follow-up assessment was self-reported - obtained by telephone interview. A cross sectional study by Nakamura et al. involved data collected exclusively by self-completed questionnaires from 96,794 Japanese men and women aged 65 years over [5]. They found that fewer than 20 
natural teeth and poor food intake were both associated with weight loss of $2 \sim 3 \mathrm{~kg}$ over a 6-month period [5]. All data in their study were self-reported including weight loss and number of teeth.

The strengths of the present study include the measurement of body weight at two points in time and the objective assessments of oral health, with an interval of 3 years apart. However, it is acknowledged that the final study sample size was relatively small. A further strength of this study is that the CHAMP study has been designed to include a representative group of older community-dwelling Australian men, as shown by the similarity of sociodemographic and health characteristics compared to the nationally representative MATeS study [32]. However, a cautious interpretation is necessary when generalizing our study results to older males throughout Australia as this was an urban population, did not include rural or regional sampling, and other state populations of Australia have a different ethnic diversity and socioeconomic factors.

The main limitation is that the study analyzed cohort data on weight changes over a 3-year period, while the other information, including oral health and appetite, was collected only in year- 8 of the study. Thus, the direction of the relationship of weight loss with oral health conditions and appetite cannot be definitely clarified. Malnutrition was solely evaluated by weight loss in our study, not considering BMI. Unintentional weight loss is related to an increased risk of all-causes of mortality in many studies, yet the magnitude of effect is different by levels of BMI [33, 34]. The association of BMI with mortality has been well established [35].

We did not use BMI as a dependent variable as there were only 4 participants who had a BMI $\leq 18.5$ at 5 th-year assessment. Future research would be more meaningful if both BMI and weight loss were included. A further limitation is that a large number of participants were lost by the follow up assessment. This may have resulted in potential selection biases. The smaller number of participants also reduced the power of statistical tests to detect significant associations between oral health and weight loss. Nonresponders and people living at residential aged care facilities tend to be older and more likely to experience unintentional weight loss. It is therefore possible that factors associated with weight loss were not fully accounted for in our analysis. The study may also be influenced by survival bias, where health status of the surviving participants is better compared with those who died or withdrew. A final limitation is that our study only included community living older men, which may limit generalizability to older men living in aged care facilities or older women.

\section{Conclusions}

In conclusion, this study found that the number of natural teeth present and appetite are independently related to weight change among community dwelling elderly men in Australia. Our findings indicate that participants with fewer than 20 natural teeth, and those with poorer appetite are at a higher risk of weight loss. Tooth loss can increase the risk of swallowing difficulty leading to change in food preference, avoidance of foods and a decrease in energy intake. Our study shows the importance of oral health interventions to encourage maintenance of 20 or more natural teeth in older people. Further research using longitudinal data is required to fully elucidate how the number of natural teeth relates to weight loss, and how appetite is related to oral health factors such as swallowing, chewing, and mouth dryness.

\section{Abbreviations \\ BMI: Body mass index; CHAMP: the Concord Health and Ageing in Men Project; Cl: Confidence interval; FTUs: Functional Tooth Units; PR: the prevalence ratio; SD: Standard deviation}

\section{Acknowledgements \\ The authors would like to thank all CHAMP's staff and participants for their contributions. We would also like to acknowledge Steven Chu, Kate Milledge, Melissa Casey and Garry Law for their assistance, data collection and advice on the study. We acknowledge the Australian government for granting the Endeavour Research Fellowship to Dr. Sachiko Takehara to work at the Centre for Education and Research on Ageing, The University of Sydney.}

\section{Authors' contributions}

$\mathrm{VH}, \mathrm{CW}, \mathrm{LW}, \mathrm{VN}, \mathrm{FB}, \mathrm{DC}, \mathrm{MS}, \mathrm{DH}$, and $\mathrm{RC}$ designed the oral health and the principal Wave 3 and 4 CHAMP study. ST, VH and FW designed this project. ST analyzed and interpreted data with support from VH, FW and RC. ST drafted the manuscript in consultation with VH, CW and RC. All authors discussed the results and contributed to the final manuscript. The author(s) read and approved the final manuscript.

\section{Funding}

This study was made possible using the data collected by the Concord Health and Ageing in Men Project (CHAMP). Funding for the CHAMP is provided by National Health and Medical Research Council (301916), Ageing and Alzheimer's Institute, and the Australian Research Council Centre of Excellence in Population Ageing Research (CEPAR). This work was also supported by JSPS KAKENHI Grant-in-Aid for Scientific Research (C) JP19K10439.

\section{Availability of data and materials}

The datasets generated during and/or analyzed during the current study are available from the corresponding author on reasonable request with permission of the CHAMP Management Team.

\section{Declarations}

Ethics approval and consent to participate

The study was performed in accordance with World Medical Association Declaration of Helsinki, and the study protocol and consent procedures were approved by Sydney Local Health District Human Ethics Research Committee (Approval No. HERC/14/CRGH/17). All participants were given a verbal explanation of study purpose and methods involved and signed consent forms

\section{Consent for publication}

Not applicable.

Competing interests

The authors declare that they have no competing interests. 


\section{Author details}

${ }^{1}$ Centre for Education and Research on Ageing, Concord Clinical School, The University of Sydney, and the Ageing and Alzheimer's Institute, Concord Repatriation General Hospital, Sydney Local Health District, Concord, NSW, Australia. 'Department of Public Health, Tokyo Women's Medical University, Tokyo, Japan. ${ }^{3}$ School of Life and Environmental Sciences, Charles Perkins Centre, The University of Sydney, Sydney, NSW, Australia. ${ }^{4}$ Concord Clinical School, Concord Repatriation General Hospital, The University of Sydney, Concord, NSW, Australia. ${ }^{5}$ Department of Geriatric Medicine and Rehabilitation Medicine, Concord Repatriation General Hospital, Sydney Local Health District, Concord, NSW, Australia. ${ }^{6}$ School of Public Health, Sydney Medical School, The University of Sydney, Sydney, NSW, Australia. ${ }^{7}$ ANZAC Research Institute, The University of Sydney, Concord Hospital, Sydney, NSW, Australia.

Received: 6 October 2020 Accepted: 21 March 2021

Published online: 16 April 2021

\section{References}

1. Wallace JI, Schwartz RS, LaCroix AZ, Uhlmann RF, Pearlman RA. Involuntary weight loss in older outpatients: incidence and clinical significance. J Am Geriatr Soc. 1995;43(4):329-37.

2. Newman AB, Yanez D, Harris T, Duxbury A, Enright PL, Fried LP. Weight change in old age and its association with mortality. J Am Geriatr Soc. 2001; 49(10):1309-18.

3. Weyant RJ, Newman AB, Kritchevsky SB, Bretz WA, Corby PM, Ren D, et al. Periodontal disease and weight loss in older adults. J Am Geriatr Soc. 2004; 52(4):547-53.

4. Ritchie CS, Joshipura K, Silliman RA, Miller B, Douglas CW. Oral health problems and significant weight loss among community-dwelling older adults. J Gerontol A Biol Sci Med Sci. 2000;55(7):M366-71.

5. Nakamura M, Ojima T, Nakade M, Ohtsuka R, Yamamoto T, Suzuki K, et al. Poor Oral health and diet in relation to weight loss, stable underweight, and obesity in community-dwelling older adults: a cross-sectional study from the JAGES 2010 project. J Epidemiol. 2016;26(6):322-9.

6. Pilgrim AL, Robinson SM, Sayer AA, Roberts HC. An overview of appetite decline in older people. Nursing Older People. 2015;27(5):29-35.

7. Whitelock E, Ensaff H. On Your Own: Older Adults' Food Choice and Dietary Habits. Nutrients. 2018;10(4):413. https://doi.org/10.3390/nu10040413.

8. Kamdem B, Seematter-Bagnoud L, Botrugno F, Santos-Eggimann B. Relationship between oral health and Fried's frailty criteria in communitydwelling older persons. BMC Geriatr. 2017;17(1):174.

9. Ikebe K, Matsuda K, Morii K, Nokubi T, Ettinger RL. The relationship between oral function and body mass index among independently living older Japanese people. Int J Prosthodont. 2006;19(6):539-46.

10. Cumming RG, Handelsman D, Seibel MJ, Creasey H, Sambrook P, Waite L, et al. Cohort profile: the Concord health and ageing in men project (CHAM P). Int J Epidemiol. 2009;38(2):374-8.

11. Bleicher K, Cumming RG, Naganathan V, Travison TG, Sambrook PN, Blyth FM, et al. The role of fat and lean mass in bone loss in older men: findings from the CHAMP study. Bone. 2011;49(6):1299-305.

12. Lee CG, Boyko EJ, Nielson CM, Stefanick ML, Bauer DC, Hoffman AR, et al. Mortality risk in older men associated with changes in weight, lean mass, and fat mass. J Am Geriatr Soc. 2011;59(2):233-40.

13. Wright FAC, Law GG, Milledge KL, Chu SK, Hsu B, Valdez E, et al. Chewing function, general health and the dentition of older Australian men: the Concord health and ageing in men project. Community Dent Oral Epidemiol. 2019:47(2):134-41.

14. Kayser AF. Shortened dental arches and oral function. J Oral Rehabil. 1981; 8(5):457-62.

15. Ueno M, Yanagisawa T, Shinada K, Ohara S, Kawaguchi Y. Masticatory ability and functional tooth units in Japanese adults. J Oral Rehabil. 2008:35(5): 337-44.

16. Walsh $L$ J. Preventive dentistry for the general dental practitioner. Aust Dent J. 2000:45(2):76-82.

17. Wright F, Chu SY, Milledge KL, Valdez E, Law G, Hsu B, et al. Oral health of community-dwelling older Australian men: the Concord health and ageing in men project (CHAMP). Aust Dent J. 2018;63(1):55-65

18. Leake JL. An index of chewing ability. J Public Health Dent. 1990;50(4):262-7.
19. van der Meij BS, Wijnhoven HAH, Lee JS, Houston DK, Hue T, Harris TB, et al. Poor appetite and dietary intake in community-dwelling older adults. J Am Geriatr Soc. 2017;65(10):2190-7.

20. Wright FAC, Takehara S, Stanaway FF, Naganathan V, Blyth FM, Hirani V, et al. Associations between oral health and depressive symptoms: Findings from the Concord Health and Ageing in Men Project. Australas J Ageing. 2020;39(3):e306-14. https://doi.org/10.1111/ajag.12763.

21. Stanaway FF, Cumming RG, Naganathan V, Blyth FM, Creasey HM, Waite LM, et al. Depressive symptoms in older male Italian immigrants in Australia: the Concord health and ageing in men project. Med J Aust. 2010;192(3):158-62.

22. Marc LG, Raue PJ, Bruce ML. Screening performance of the 15-item geriatric depression scale in a diverse elderly home care population. Am J Geriatric Psychiatry. 2008;16(11):914-21. https://doi.org/10.1097/ JGP.0b013e318186bd67.

23. Valdez E, Wright FAC, Naganathan V, Milledge K, Blyth FM, Hirani V, et al. Frailty and oral health: findings from the Concord health and ageing in men project. Gerodontology. 2020;37(1):28-37.

24. Fried LP, Tangen CM, Walston J, Newman AB, Hirsch C, Gottdiener J, et al. Frailty in older adults: evidence for a phenotype. J Gerontol A Biol Sci Med Sci. 2001;56(3):M146-56.

25. Zhang J, Yu KF. What's the relative risk? A method of correcting the odds ratio in cohort studies of common outcomes. Jama. 1998;280(19):1690-1.

26. Hayes AF, Rockwood NJ. Regression-based statistical mediation and moderation analysis in clinical research: observations, recommendations, and implementation. Behav Res Ther. 2017;98:39-57.

27. Solemdal K, Sandvik L, Willumsen T, Mowe M, Hummel T. The impact of oral health on taste ability in acutely hospitalized elderly. PLoS One. 2012;7(5):e36557.

28. Malafarina V, Uriz-Otano F, Gil-Guerrero L, Iniesta R. The anorexia of ageing: physiopathology, prevalence, associated comorbidity and mortality. A systematic review. Maturitas. 2013;74(4):293-302.

29. Dormenval V, Budtz-Jørgensen E, Mojon P, Bruyère A, Rapin $\mathrm{CH}$. Associations between malnutrition, poor general health and oral dryness in hospitalized elderly patients. Age Ageing. 1998;27(2):123-8.

30. Kamel UF, Maddison P, Whitaker R. Impact of primary Sjogren's syndrome on smell and taste: effect on quality of life. Rheumatology (Oxford, England). 2009:48(12):1512-4.

31. Donini LM, Dominguez LJ, Barbagallo M, Savina C, Castellaneta E, Cucinotta $D$, et al. Senile anorexia in different geriatric settings in Italy. J Nutr Health Aging. 2011;15(9):775-81.

32. Holden CA, McLachlan Rl, Pitts M, Cumming R, Wittert G, Agius PA, et al. Men in Australia telephone survey (MATeS): a national survey of the reproductive health and concerns of middle-aged and older Australian men. Lancet. 2005:366(9481):218-24.

33. Myrskyla M, Chang WW. Weight change, initial BMl, and mortality among middle- and older-aged adults. Epidemiology. 2009;20(6):840-8.

34. Yaari S, Goldbourt U. Voluntary and involuntary weight loss: associations with long term mortality in 9,228 middle-aged and elderly men. Am J Epidemiol. 1998;148(6):546-55.

35. Global BMIMC, Di Angelantonio E, Bhupathiraju Sh N, Wormser D, Gao P, Kaptoge $S$, et al. Body-mass index and all-cause mortality: individualparticipant-data meta-analysis of 239 prospective studies in four continents. Lancet. 2016;388(10046):776-86.

\section{Publisher's Note}

Springer Nature remains neutral with regard to jurisdictional claims in published maps and institutional affiliations.

Ready to submit your research? Choose BMC and benefit from:

- fast, convenient online submission

- thorough peer review by experienced researchers in your field

- rapid publication on acceptance

- support for research data, including large and complex data types

- gold Open Access which fosters wider collaboration and increased citations

- maximum visibility for your research: over $100 \mathrm{M}$ website views per year

At $\mathrm{BMC}$, research is always in progress.

Learn more biomedcentral.com/submission 